\title{
Analisa Heat Balance Thermal Oxidizer dengan Waste Heat Recovery Unit
}

\author{
Alfian Bani Susiloputra dan Bambang Arip Dwiyantoro \\ Jurusan Teknik Mesin, Fakultas Teknologi Industri, Institut Teknologi Sepuluh Nopember (ITS) \\ Jl. Arief Rahman Hakim, Surabaya 60111 Indonesia \\ e-mail: bambangads@me.its.ac.id
}

\begin{abstract}
Abstrak-Central Processing Plant (CPP) merupakan plant yang memproses feed gas hingga menjadi natural gas siap pakai. Pengolahan feed gas di CPP menimbulkan dampak limbah berupa waste gas. Thermal Oxidizer (TOX) memiliki peran penting dalam mengatasi waste gas. Energi panas gas buang (flue gas) dimanfaatkan pada Waste Heat Recovery Unit (WHRU) yang berada diatas chamber, digunakan untuk memanaskan hot oil. Kondisi operasional pembakaran TOX di CPP saat ini, jumlah input sangat berbeda dengan desain awal. Suhu pembakaran juga sangat tinggi, yaitu diatas $1.144 \mathrm{~K}$. Sementara itu WHRU belum berjalan secara normal, suhu hot oil pada outlet WHRU masih 438-444 K. Analisa pembakaran TOX dilakukan dengan analisa termodinamika pada jumlah bahan bakar serta jumlah excess air untuk mendapatkan pembakaran sempurna pada suhu ideal chamber, yaitu 1.088-1.144 K. Bahan bakar yang digunakan sejumlah 60\%-100\% dari fuel gas operasional, sedangkan excess air yang digunakan $10 \%-35 \%$. Selain itu pemanfaatan energi panas flue gas pada WHRU dilakukan analisa supaya suhu hot oil keluar WHRU mencapai 449 K. Analisa WHRU dilakukan dengan analisa perpindahan panas, untuk mendapatkan flowrate dari hot oil dari suhu dan laju aliran massa flue gas hasil variasi pembakaran TOX tersebut. Dari penelitian ini, suhu TOX hasil pembakaran operasional yang sesuai dengan desain awal yaitu pada $60 \%$ fuel gas dengan excess air (EA) antara $30 \%$ hingga $35 \%$. Pada $60 \%$ fuel gas dengan EA antara $30 \%$ hingga $35 \%$ didapatkan suhu antara $1.095 \mathrm{~K}$ hingga $1.138 \mathrm{~K}$. Pada hasil analisa WHRU, untuk mencapai suhu hot oil sebesar 449,817 K pada variasi TOX tersebut diperlukan laju aliran massa hot oil sebesar $1.257 .720 \mathrm{~kg} / \mathrm{jam}$ dan $1.481 .420 \mathrm{~kg} / \mathrm{jam}$.
\end{abstract}

Kata Kunci-excess air, pembakaran, Thermal Oxidizer, Waste Heat Recovery Unit.

\section{PENDAHULUAN}

CEN ENTRAL Processing Plant (CPP) merupakan plant yang memproses feed gas hingga menjadi natural gas siap pakai. Feed gas dari sumur produksi memasuki inlet manifold yang kemudian diolah pada Gas Separation Unit (GSU) untuk memisahkan air dan kondensat yang terbawa dari sumur produksi. Setelah itu feed gas memasuki Acid Gas Removal Unit (AGRU) untuk memisahkan kandungan acid gas yang ada. Treated gas hasil pengolahan AGRU selanjutnya memasuki Caustic Treater Unit (CTU) untuk menghilangkan mercaptant yang terkandung didalam treated gas. Kemudian treated gas menuju Dehydration Unit untuk menurunkan kadar air.

Dari pengolahan feed gas di CPP menimbulkan dampak limbah berupa waste gas, terdiri dari acid gas dan vent gas, yang diolah terlebih dahulu sebelum dilepas ke lingkungan. Acid gas dengan kandungan $\mathrm{H}_{2} \mathrm{~S}$ yang sangat tinggi diolah dalam dua jalur, yaitu langsung dibakar pada Thermal Oxidizer
(TOX) dan diproses pada Biological Sulphur Recovery Unit (BSRU) untuk menyerap kandungan sulfur melalui reaksi pada bioreaktor yang kemudian bisa dipadatkan pada Sulphur Melter \& Solidification Unit. Namun, tidak semua acid gas terolah pada BSRU, sehingga limbah acid gas sisa dari BSRU dibakar pada TOX. Sementara itu untuk vent gas dari berbagai unit pengolahan langsung dibakar pada TOX.

Thermal Oxidizer (TOX) memiliki peran penting dalam mengatasi waste gas. Kinerja TOX ditentukan dari proses pembakaran yang terjadi pada burner harus sempurna serta suhu oksidasi waste gas pada chamber harus sesuai. Jumlah udara tambahan (excess air) yang diberikan pada burner TOX harus diperhitungkan, karena excess air dengan jumlah yang tidak tepat bisa merugikan pembakaran dan suhu pada chamber tidak sesuai. Energi panas gas buang (flue gas) dimanfaatkan pada Waste Heat Recovery Unit (WHRU) yang berada diatas chamber. WHRU berupa heat exchanger yang digunakan untuk memanaskan hot oil. Peran WHRU dalam memanaskan hot oil hingga $350^{\circ} \mathrm{F}(449,8 \mathrm{~K})$ juga sangat penting, karena hot oil digunakan pada Solvent Regenerator Reboiler.

Kondisi operasional pembakaran pada TOX di CPP saat ini, jumlah input sangat berbeda dengan desain awal TOX dan suhu pembakaran sangat tinggi, yaitu diatas $1.600^{\circ} \mathrm{F}(1.144 \mathrm{~K})$. Sementara itu WHRU belum berjalan secara normal yang mengakibatkan energi panas flue gas banyak yang terbuang siasia sehingga suhu keluaran dari stack masih sangat tinggi, yaitu lebih dari $700^{\circ} \mathrm{F}(644 \mathrm{~K})$, serta suhu hot oil pada outlet WHRU hanya $330-340^{\circ} \mathrm{F}(438-444 \mathrm{~K})$. Berdasarkan kondisi TOX saat ini di CPP, pembakaran pada TOX serta pemanfaatan energi panas pada WHRU perlu dilakukan evaluasi dengan analisa heat balance. Analisa heat balance dilakukan dengan analisa termodinamika pada sistem pembakaran TOX dan analisa perpindahan panas pada WHRU.

\section{URAIAN PENELITIAN}

\section{A. Analisa Pembakaran}

Dalam kesetimbangan reaksi kimia pembakaran dibutuhkan sejumlah udara pembakaran untuk menghasilkan pembakaran sempurna. Reaksi-reaksi pembakaran dinyatakan dalam persamaan kimia di dalam bentuk [reaktan $\rightarrow$ produk]. Pendekatan reaksi kimia pembakaran sempurna sebagai berikut [1] : 


$$
\begin{aligned}
C_{x} H_{y} S_{z}+ & \left(x+\frac{y}{4}+z\right)\left(O_{2}+3,76 N_{2}\right) \stackrel{\text { panas }}{\longrightarrow} x \mathrm{CO}_{2}+ \\
& \frac{y}{2} \mathrm{H}_{2} \mathrm{O}+\mathrm{zSO}_{2}+\left(x+\frac{y}{4}+z\right) 3,76 \mathrm{~N}_{2}
\end{aligned}
$$

Dari hasil reaksi pembakaran, didapatkan rasio udara-bahan bakar dengan basis molar dan basis massa sebagai berikut.

$$
\begin{gathered}
\overline{A F}=\frac{\text { mol udara }}{\text { mol bahan bakar }} \\
A F=\overline{A F}\left(\frac{M_{\text {udara }}}{M_{\text {bahan bakar }}}\right)
\end{gathered}
$$

dengan

$M=$ berat molekuler $(\mathrm{kg} / \mathrm{kmol})$

$\overline{A F}=$ rasio udara bahan bakar basis molar $(\mathrm{kmol} / \mathrm{kmol})$

$A F=$ rasio udara bahan bakar basis massa $(\mathrm{kg} / \mathrm{kg})$

Sebuah reaksi yang terjadi secara eksotermik, supaya produk dapat keluar pada temperatur yang sama dengan elemen-elemen yang masuk, diperlukan adanya perpindahan panas dari reaktor ke lingkungan sekitarnya. Laju perpindahan kalor dan entalpi dari aliran yang masuk dan keluar saling berhubungan dengan kesetimbangan laju energi.

$$
\frac{\dot{Q}_{c v}}{\dot{n}_{F}}-\frac{\dot{W}_{c v}}{\dot{n}_{F}}=\sum_{P} n_{e}\left(\bar{h}_{f}^{o}+\Delta \bar{h}\right)_{e}-\sum_{R} n_{i}\left(\bar{h}_{f}^{o}+\Delta \bar{h}\right)_{i}
$$

dengan

$n=$ jumlah mol

$\dot{n}=$ laju aliran $\mathrm{mol}(\mathrm{kmol} / \mathrm{jam})$

$\overline{h_{f}^{o}}=$ entalpi pembentukan basis molar $(\mathrm{kJ} / \mathrm{kmol})$

$\overline{\Delta h}=$ perubahan entalpi basis molar dari kondisi referensi $(\mathrm{kJ} / \mathrm{kmol})$

$\dot{Q}_{c v}=$ laju aliran panas melalui control volume $(\mathrm{kJ} / \mathrm{jam})$

$\dot{W}_{c v}=$ laju aliran kerja melalui control volume $(\mathrm{kJ} / \mathrm{jam})$

indeks $i$ dan $e=$ fluida masuk dan keluar ruang bakar

Pada suatu reaktor yang bekerja pada kondisi tunak, apabila tanpa adanya kerja $\dot{W}_{c v}$ serta efek energi kinetik dan potensial, energi yang dilepaskan ketika terjadi pembakaran dipindahkan dari reaktor hanya melalui dua cara, yaitu melalui energi yang menyertai produk hasil pembakaran yang keluar dan melalui perpindahan kalor ke lingkungan sekitar. Temperatur yang akan dicapai oleh produk hasil pembakaran di dalam limit pengoperasian adiabatik dari reaktor tersebut disebut dengan temperatur api adiabatik atau temperatur pembakaran adiabatik. Temperatur api adiabatik dapat ditentukan dengan menggunakan prinsip-prinsip konversi massa dan konversi energi.

$$
\sum_{P} n_{e}(\Delta \bar{h})_{e}=\sum_{R} n_{i}(\Delta \bar{h})_{i}+\sum_{R} n_{i} \bar{h}_{f i}^{o}-\sum_{P} n_{e} \bar{h}_{f e}^{o}
$$

Temperatur api adiabatik ditentukan dengan cara iterasi karena temperatur yang tidak diketahui tersebut muncul di dalam setiap suku di dalam penjumlahan di sisi kiri persamaan (5).

\section{B. Analisa Perpindahan Panas pada WHRU}

Compact heat exchanger merupakan salah satu dari jenis alat penukar panas, dimana tube bank yang disusun secara aligned atau staggered dengan salah satu jenis fin yang tepasang. Dalam analisa heat exchanger perlu didefinisikan koefisien perpindahan panas total, dapat dihitung berdasarkan persamaan [2],[3] :

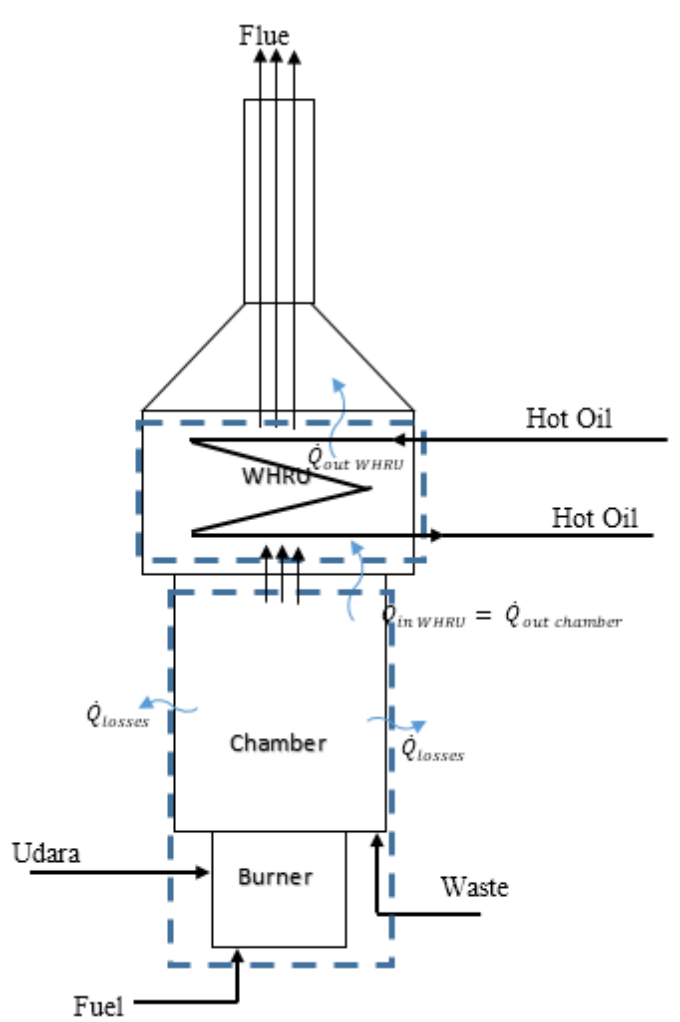

Gambar. 1. Kesetimbangan energi dan massa pada TOX dan WHRU

$$
\frac{1}{U A}=\frac{1}{(\mathrm{~h} A)_{c}}+\frac{R_{f . c}^{\prime \prime}}{A_{c}}+R_{w}+\frac{R_{f . h}^{\prime \prime}}{\left(\eta_{o} A\right)_{h}}+\frac{1}{\left(\eta_{o} \mathrm{~h} A\right)_{h}}
$$

dengan

$h=$ koefisien perpindahan panas konveksi $\left(\mathrm{W} / \mathrm{m}^{2} \mathrm{~K}\right)$

$A=$ luasan $\left(\mathrm{m}^{2}\right)$

$R=$ hambatan termal $(\mathrm{K} / \mathrm{W})$

$R_{f}{ }_{f}=$ fouling factor $\left(\mathrm{m}^{2} \mathrm{~K} / \mathrm{W}\right)$

$\eta=$ efisiensi fin

$U=$ koefisien perpindahan panas total $\left(\mathrm{W} / \mathrm{m}^{2} \mathrm{~K}\right)$

indeks $c$ dan $h=$ fluida dingin dan panas

Pada sisi bagian dalam tube, koefisien perpindahan panas konveksi dapat dihitung dengan rumus sebagai berikut :

$$
\begin{gathered}
R e_{D}=\frac{4 \dot{m}}{N_{\text {in }} \pi D_{i} \mu} \\
N u=0,023 \operatorname{Re}_{D}^{4 / 5} \operatorname{Pr}^{0,4} \\
h=\frac{N u k}{D_{i}}
\end{gathered}
$$

dengan

$R e_{D}=$ Reynold number dalam tube

$\dot{m}=$ laju aliran massa $(\mathrm{kg} / \mathrm{jam})$

$N_{\text {in }}=$ jumlah tube pada untuk inlet

$D_{i}=$ diameter dalam (m)

$\mu=$ viskositas dinamik $\left(\mathrm{Ns} / \mathrm{m}^{2}\right)$

$\mathrm{Nu}=$ Nusselt number

$\operatorname{Pr}=$ Prandlt number

$h=$ koefisien perpindahan panas konveksi $\left(\mathrm{W} / \mathrm{m}^{2} \mathrm{~K}\right)$

Pada sisi bagian luar tube, koefisien perpindahan panas konveksi dapat dihitung dengan rumus sebagai berikut [4] :

$$
V_{\max }=\frac{S_{T}}{S_{T}-D_{o}} V
$$




$$
\begin{gathered}
D_{h}=4 \frac{T A_{o}}{A_{\text {total }}} \\
R e_{h}=\frac{\rho V_{\max } D_{h}}{\mu} \\
\overline{N u}_{h}=0,134 R e^{0,681} \operatorname{Pr}^{1 / 3}\left(\frac{s}{l}\right)^{0,2}\left(\frac{s}{t}\right)^{0,1134} \\
\bar{h}_{h}=\frac{\overline{N u} k}{D_{h}}
\end{gathered}
$$

dengan

$V_{\max }=$ kecepatan maksimum melalui sisi luar tube $(\mathrm{m} / \mathrm{s})$

$S_{T}=$ jarak transfersal tube $(\mathrm{m})$

$D_{o}=$ diameter luar tube $(\mathrm{m})$

$D_{h}=$ diameter hidraulik (m)

$T=$ tinggi laluan fluida panas $(\mathrm{m})$

$A_{o}=$ net free flow area $\left(\mathrm{m}^{2}\right)$

$\rho=$ massa jenis $\left(\mathrm{kg} / \mathrm{m}^{3}\right)$

$s=$ jarak antar tube $(\mathrm{m})$

$l=$ panjang $f$ in $(\mathrm{m})$

$t=$ tebal fin $(\mathrm{m})$

Dengan menggunakan variabel overall heat transfer coefficient dan total luas permukaan perpindahan panas, laju perpindahan panas dapat dihitung dengan metode LMTD ( $\log$ Mean Temperature Difference). Untuk heat exchanger tipe compact cross flow, digunakan $\Delta T$ Tlm counter flow dengan faktor koreksi $F$ dalam perhitungan laju aliran panas, sehingga [5] :

$$
\dot{Q}=U A F \Delta T_{l m . c f}
$$

Nilai $F$ didapatkan dengan menentukan rasio $P$ dan $R$ yang dihitung persamaan berikut :

$$
\begin{aligned}
& P=\frac{T_{c 2}-T_{c 1}}{T_{h 1}-T_{c 1}} \\
& R=\frac{T_{h 1}-T_{h 2}}{T_{c 2}-T_{c 1}}
\end{aligned}
$$

dengan

$T=$ temperatur $(\mathrm{K})$

indeks 1 dan 2 = kondisi masuk dan keluar

\section{Tahapan Analisa}

Data utama yang digunakan dalam analisa pembakaran pada TOX yaitu data waste gas yang berasal dari berbagai unit proses pengolahan di CPP. Data tersebut akan dihitung dengan analisa termodinamika untuk mengetahui kesesuaian antara teoritis dan kondisi aktual. Setelah itu, akan dilakukan perhitungan jumlah bahan bakar dan air fuel ratio secara termodinamika dan dilakukan variasi jumlah excess air untuk pembakaran TOX, dengan tujuan untuk mendapatkan nilai yang tepat dalam pembakaran. Selanjutnya dilakukan analisa pada WHRU dengan analisa perpindahan panas. Analisa awal akan dilakukan perhitungan ulang kondisi operasi saat ini untuk mengetahui kesesuaian antara teoritis dan kondisi aktual. Selanjutnya akan dilakukan perhitungan flow rate dari hot oil pada sisi tube untuk mendapatkan suhu outlet $350^{\circ} \mathrm{F}\left(176,6^{\circ} \mathrm{C}\right)$.

\section{HASIL DAN DISKUSI}

\section{A. Analisa Pembakaran pada TOX}

Pembakaran pada TOX yang akan dianalisa berupa data

\begin{tabular}{|c|c|c|c|c|c|c|c|}
\hline Excess Air & $0 \%$ & $10 \%$ & $15 \%$ & $20 \%$ & $25 \%$ & $30 \%$ & 35\% \\
\hline $\begin{array}{r}\mathrm{h} \text { flue gas } \\
(\mathrm{kJ} / \mathrm{kg})\end{array}$ & $2.108,9$ & $1.970,9$ & $1.908,5$ & $1.849,9$ & $1.794,8$ & $1.742,9$ & $1.693,9$ \\
\hline
\end{tabular}
desain dan data operasional. Untuk data desain tidak dilakukan variasi karena hanya untuk pengecekan, sedangkan untuk data operasional akan dilakukan variasi excess air antara 10-35\% dengan kenaikan 5\% dan variasi flowrate 60\%-100\% fuel gas dari flowrate operasional dengan kenaikan $20 \%$.

Tabel 1.

Tabel 2.

Hasil Perhitungan $\Delta$ h Flue Gas $80 \%$ Flowrate Fuel Gas

\begin{tabular}{rccccccc}
\hline \hline Excess Air & $\mathbf{0 \%}$ & $\mathbf{1 0 \%}$ & $\mathbf{1 5 \%}$ & $\mathbf{2 0 \%}$ & $\mathbf{2 5 \%}$ & $\mathbf{3 0 \%}$ & $\mathbf{3 5 \%}$ \\
\hline $\begin{array}{r}\Delta \mathrm{h} \text { flue gas } \\
(\mathrm{kJ} / \mathrm{kg})\end{array}$ & $2.084,9$ & $1.950,1$ & $1.889,0$ & $1.831,7$ & $1.777,7$ & $1.726,8$ & $1.678,8$ \\
\hline \hline
\end{tabular}

Tabel 3.

Hasil Perhitungan $\triangle$ h Flue Gas $60 \%$ Flowrate Fuel Gas

\begin{tabular}{rccccccc}
\hline \hline Excess Air & $\mathbf{0 \%}$ & $\mathbf{1 0 \%}$ & $\mathbf{1 5 \%}$ & $\mathbf{2 0 \%}$ & $\mathbf{2 5 \%}$ & $\mathbf{3 0 \%}$ & $\mathbf{3 5 \%}$ \\
\hline $\begin{array}{r}\Delta \mathrm{h} \text { flue gas } \\
(\mathrm{kJ} / \mathrm{kg})\end{array}$ & $2.059,0$ & $1.927,6$ & $1.868,0$ & $1.812,0$ & $1.759,2$ & $1.709,4$ & $1.662,4$ \\
\hline \hline
\end{tabular}

Tabel 4.

Hasil Suhu Flue Gas Pembakaran TOX pada Data Operasional

\begin{tabular}{crrr}
\hline \hline Flowrate Fuel Gas & Excess Air & T Flue Gas (K) & T in WHRU (K) \\
\hline $60 \%$ & $0 \%$ & $1.495,811$ & $1.489,241$ \\
$10 \%$ & $1.355,029$ & $1.349,495$ \\
& $15 \%$ & $1.293,970$ & $1.288,872$ \\
$20 \%$ & $1.237,772$ & $1.233,067$ \\
$25 \%$ & $1.186,581$ & $1.182,228$ \\
& $30 \%$ & $1.138,908$ & $1.134,875$ \\
& $35 \%$ & $1.095,440$ & $1.091,694$ \\
$80 \%$ & $0 \%$ & $1.509,288$ & $1.502,852$ \\
& $10 \%$ & $1.366,145$ & $1.360,732$ \\
& $15 \%$ & $1.304,103$ & $1.299,120$ \\
& $20 \%$ & $1.247,010$ & $1.242,415$ \\
& $25 \%$ & $1.194,900$ & $1.190,652$ \\
& $30 \%$ & $1.146,675$ & $1.142,741$ \\
& $35 \%$ & $1.102,534$ & $1.098,884$ \\
$100 \%$ & $0 \%$ & $1.521,766$ & $1.515,459$ \\
& $10 \%$ & $1.376,456$ & $1.371,160$ \\
& $15 \%$ & $1.313,435$ & $1.308,564$ \\
& $20 \%$ & $1.255,564$ & $1.251,003$ \\
& $25 \%$ & $1.202,746$ & $1.198,599$ \\
& $30 \%$ & $1.153,857$ & $1.150,019$ \\
& $35 \%$ & $1.109,091$ & $1.105,532$ \\
\hline \hline
\end{tabular}

Berdasarkan penelitian ini didapatkan beberapa grafik perbandingan perubahan entalpi $(\Delta h)$ dan suhu dari flue gas hasil pembakaran di TOX.

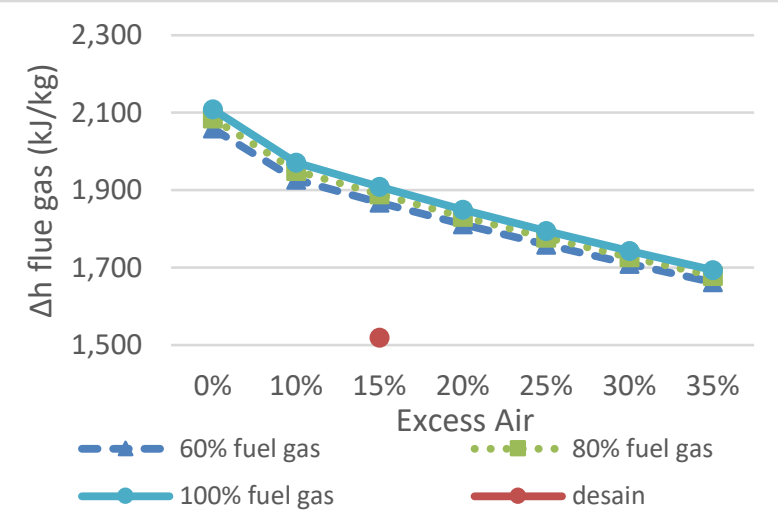

Gambar. 2. Grafik perbandingan $\Delta h_{\text {flue gas }}=\mathrm{f}(E A)$ pada $60 \%, 80 \%$ dan $100 \%$ fuel gas 
Pada gambar 2, perubahan entalpi pada data desain dan data operasional terdapat perbedaan yang cukup jauh, hal tersebut dikarenakan input operasional lebih tinggi dibandingkan input desain awal TOX. Pada grafik 60\%, 80\%, dan 100\% fuel gas terlihat penurunan perubahan entalpi $(\Delta h)$ flue gas seiring dengan meningkatnya excess air. Hal tersebut terjadi karena pada saat excess air meningkat, maka laju aliran massa pada flue gas juga akan meningkat. Selain itu pada saat excess air meningkat, heat rate dari entalpi pembentukan produk tidak mengalami perubahan, hal tersebut dikarenakan entalpi pembentukan produk dihitung berdasarkan udara teori yang dibutuhkan pembakaran. Pada grafik hasil perhitungan sesuai dengan teori, yaitu semakin besar jumlah excess air, maka perubahan entalpi $(\Delta h)$ flue gas akan semakin rendah. Analisa perhitungan yang digunakan merupakan proses pembakaran secara teoritis, sehingga nilai terbaik terdapat pada stoikiometri (excess air 0\%), penambahan excess air mengurangi panas pembakaran.

Dari gambar 2 terlihat selisih perubahan entalpi $(\Delta h)$ flue gas antara 60\%-100\% fuel gas. Selisih perubahan entalpi pada setiap variasi excess air juga berbeda-beda, semakin besar excess air terlihat perbedaan semakin kecil, serta semakin kecil jumlah fuel gas terlihat perbedaan semakin besar.

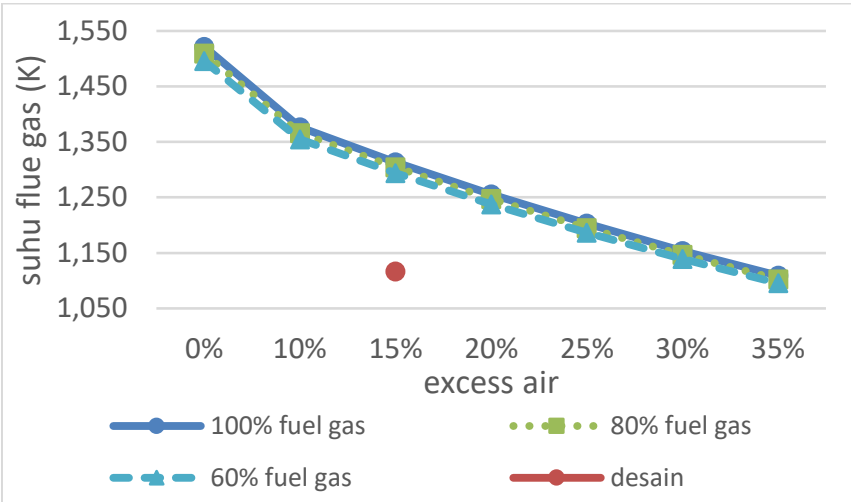

Gambar. 3. Grafik perbandingan $\mathrm{T}_{\text {flue gas }}=\mathrm{f}(\mathrm{EA})$ pada $60 \%, 80 \%$ dan $100 \%$ fuel gas

Pada gambar 3, pada grafik $60 \%, 80 \%$, dan $100 \%$ fuel gas terlihat penurunan suhu flue gas seiring dengan meningkatnya excess air. Hal tersebut terjadi karena pada saat excess air meningkat, maka laju aliran massa pada flue gas juga akan meningkat. Ketika laju aliran massa flue gas meningkat akan mengakibatkan kehilangan panas pada pembakaran juga meningkat. Oleh karena itu, suhu flue gas akan mengalami punurunan. Analisa perhitungan yang digunakan merupakan proses pembakaran secara teoritis, sehingga nilai terbaik terdapat pada stoikiometri (excess air 0\%), penambahan excess air mengurangi panas pembakaran.

Dari gambar 3 terlihat selisih suhu flue gas antara $60 \%, 80 \%$, dan $100 \%$ fuel gas. Selisih perubahan entalpi pada setiap variasi excess air juga berbeda-beda, semakin besar excess air terlihat perbedaan semakin kecil, serta semakin kecil fuel gas terlihat perbedaan semakin besar.

Pada dasarnya perubahan jumlah bahan bakar tidak mempengaruhi nilai perubahan entalpi $(\Delta h)$ dan suhu pembakaran. Namun, pembakaran yang terjadi pada TOX terdapat input waste gas yang merupakan senyawa tidak menngalami reaksi pembakaran, seperti $\mathrm{CO}_{2}$ dan $\mathrm{N}_{2}$. Oleh karena itu, pembakaran pada TOX ketika dilakukan variasi penurunan jumlah bahan bakar terjadi sedikit penurunan perubahan entalpi $(\Delta h)$ dan suhu. Dari gambar 4 dan 5 menunjukkan bahwa mengurangi flowrate fuel gas sebesar $20 \%$ tidak berdampak banyak pada perubahan entalpi dan suhu pada flue gas. Sehingga, pengurangan jumlah fuel gas bisa dilakukan untuk menghemat konsumsi bahan bakar.

\section{B. Analisa Perpindahan Panas Pada WHRU}

Analisa perpindahan panas pada WHRU yang akan dilakukan berupa data desain dan data operasional. Untuk data operasional akan dilakukan variasi flowrate dan suhu flue gas dari hasil analisa pembakaran TOX.

Tabel 5.

Hasil perhitungan laju aliran massa dari oil

\begin{tabular}{ccccr}
\hline \hline $\begin{array}{c}\text { Jumlah } \\
\text { BB }\end{array}$ & $\begin{array}{c}\text { Excess } \\
\text { Air }\end{array}$ & $\begin{array}{c}\text { Tin WHRU } \\
(\mathbf{K})\end{array}$ & $\begin{array}{c}\text { mass rate flue } \\
\text { gas }(\mathbf{k g} / \mathbf{j a m})\end{array}$ & $\begin{array}{c}\text { Mass rate oil } \\
(\mathbf{k g} / \mathbf{j a m})\end{array}$ \\
\hline $60 \%$ & $10 \%$ & $1.349,495$ & $160.350,010$ & $696.659,45$ \\
& $15 \%$ & $1.288,872$ & $165.465,601$ & $800.286,47$ \\
& $20 \%$ & $1.233,067$ & $170.581,192$ & $925.994,02$ \\
& $25 \%$ & $1.182,228$ & $175.696,782$ & $1.074 .008,67$ \\
& $30 \%$ & $1.134,875$ & $180.812,373$ & $1.257 .720,86$ \\
& $35 \%$ & $1.091,694$ & $185.927,964$ & $1.481 .420,93$ \\
$80 \%$ & $10 \%$ & $1.360,732$ & $166.619,267$ & $644.742,15$ \\
& $15 \%$ & $1.299,120$ & $172.005,063$ & $735.912,75$ \\
& $20 \%$ & $1.242,415$ & $177.390,858$ & $844.291,00$ \\
& $25 \%$ & $1.190,652$ & $182.776,654$ & $971.693,77$ \\
& $30 \%$ & $1.142,741$ & $188.162,449$ & $1.126 .232,03$ \\
$100 \%$ & $35 \%$ & $1.098,884$ & $193.548,245$ & $1.312 .368,34$ \\
& $10 \%$ & $1.371,160$ & $172.888,524$ & $598.556,02$ \\
& $15 \%$ & $1.308,564$ & $178.544,524$ & $681.919,50$ \\
& $20 \%$ & $1.251,003$ & $184.200,524$ & $778.247,02$ \\
& $25 \%$ & $1.198,599$ & $189.856,525$ & $889.520,68$ \\
& $30 \%$ & $1.150,019$ & $195.512,525$ & $1.024 .180,16$ \\
& $35 \%$ & $1.105,532$ & $201.168,525$ & $1.183 .629,75$ \\
\hline \hline
\end{tabular}

Berdasarkan penelitian ini didapatkan grafik perbandingan jumlah laju aliran massa oil yang dibutuhkan pada WHRU.

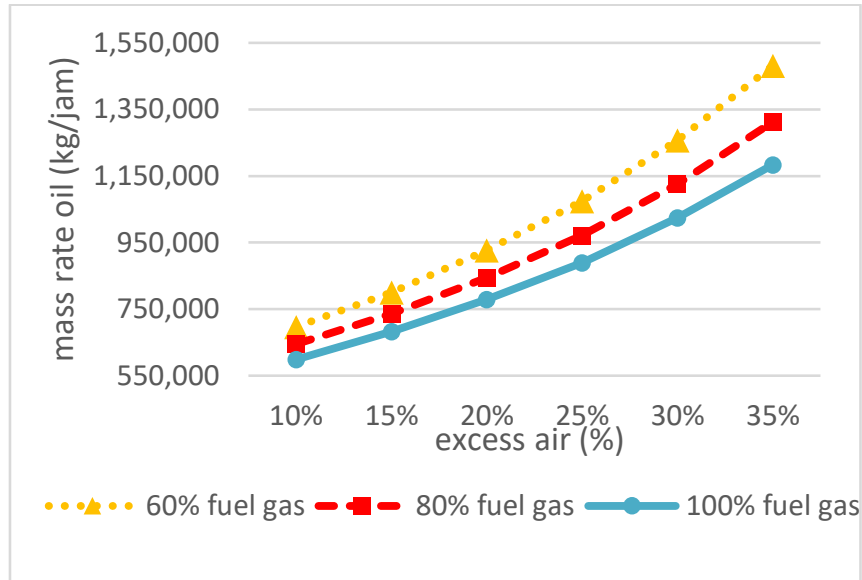

Gambar. 4. Grafik hasil laju aliran massa oil dalam WHRU

Pada gambar 4 merupakan grafik yang menunjukkan hasil laju aliran massa oil pada flue gas yang berbeda-beda hasil variasi analisa pembakaran TOX. Laju aliran massa oil tersebut merupakan jumlah yang dibutuhkan untuk mencapai suhu keluar WHRU sebesar $350^{\circ} \mathrm{F}(449,817 \mathrm{~K})$. Pada desain WHRU 
diketahui batas maksimal mass flowrate yang diperbolehkan pada oil, yaitu sebesar 1.527.072,691 kg/jam. Oleh karena itu, berdasarkan batasan tersebut pada semua variasi excess air untuk 60\%-100\% fuel gas dapat digunakan dalam operasional.

Pada grafik hasil laju aliran massa oil terlihat nilai yang terus mengalami peningkatan seiring bertambahnya excess air pada pembakaran TOX. Hal tersebut terjadi karena suhu flue gas yang semakin kecil ketika excess air semakin besar, sehingga dibutuhkan mass flowrate yang lebih banyak untuk tetap mencapai suhu oil $350^{\circ} \mathrm{F}$. Selain itu nilai mass flowrate pada flue gas semakin besar mengakibatkan diperlukan mass flowrate oil yang lebih besar agar tidak mengalami kenaikan suhu pada outlet oil.

\section{KESIMPULAN}

Berdasarkan hasil analisa heat balance pada Thermal Oxidizer dan Waste Heat Recovery Unit, dapat diambil beberapa kesimpulan sebagai berikut

1. Jika meninjau suhu flue gas hasil pembakaran TOX dari data operasional, variasi terbaik yang mendekati desain awal $\left(1.500-1600^{\circ} \mathrm{F}\right.$ atau $\left.1.088-1.144 \mathrm{~K}\right)$ yaitu pada $60 \%$ flowrate bahan bakar dengan excess air antara $30 \%$ hingga $35 \%$.

2. Dari variasi $60 \%$ flowrate bahan bakar dengan excess air antara 30\% hingga 35\%, didapatkan suhu flue gas hasil pembakaran antara 1.095,440K hingga 1.138,908K, serta suhu flue gas masuk WHRU antara 1.091,694K hingga $1.134,875 \mathrm{~K}$.

3. Dari hasil tinjauan suhu flue gas, maka laju aliran massa yang dapat diterapkan untuk mendapat suhu outlet oil sebesar $350^{\circ} \mathrm{F}$ adalah sebagai berikut

- $60 \%$ bahan bakar, $30 \%$ excess air $\rightarrow 1.257 .720,86$ $\mathrm{kg} / \mathrm{jam}$

- $\quad 60 \%$ bahan bakar, $35 \%$ excess air $\rightarrow 1.481 .420,93$ $\mathrm{kg} / \mathrm{jam}$

Jika berdasarkan data desain, laju aliran massa oil tersebut masih dibawah kondisi maksimal yaitu 1.527.072,691 $\mathrm{kg} / \mathrm{jam}$, sehingga aman digunakan dalam operasional.

4. Jumlah bahan bakar (fuel gas) sebesar 60\%, dapat menghemat konsumsi bahan bakar pada pembakaran di Thermal Oxidizer.

\section{DAFTAR PUSTAKA}

[1] Moran, M. J., dan Shapiro, H. N., Fundamental of Engineering Thermodynamics 5th Edition. Chichester : John Wiley \& Sons (2006).

[2] Incropera, F. P., dan Dewitt, D. P., Fundamental of Heat and Mass Transfer 7th Edition. New Jersey : John Wiley \& Sons (2011).

[3] Rosady, S. D., Re-Design Lube Oil Cooler pada Turbin Gas. Jurnal Teknik Pomits, Vol. 3 No. 2 (2014) 164-168.

[4] Thulukkanam, K., Heat Exchanger Design Handbook. Boca Raton : CRC Press (2013).

[5] Kakac, S., Liu, H., dan Pramuanjaroenkij, A., Heat Exchanger : Selection, Rating, and Thermal Design. Boca Raton : CRC Press (2012). 